\title{
THE JUNE MEETING AT CORVALLIS
}

The five hundred and forty-seventh meeting of the American Mathematical Society was held at Oregon State College in Corvallis, Oregon, on Saturday, June 21, 1958. There was a meeting of the Mathematical Association of America on Friday, June 20 and a meeting of the Society for Industrial and Applied Mathematics on Saturday afternoon. Among the 143 registrants at these meetings were 85 members of the Society.

By invitation of the Committee to Select Hour Speakers for Far Western Sectional Meetings, Professor Leo Sario of the University of California at Los Angeles addressed the Society Saturday morning on Problems on Riemann surfaces. He was introduced by Professor Edwin Hewitt.

There were three sessions for contributed papers with Professors R. A. Beaumont, Arthur Erdelyi and A. T. Lonseth presiding. Mr. Riggle was introduced by Professor Goheen, Mr. Hilzman by Professor Lonseth and Professor Schaefer by Professor Hacker.

R. S. PIERCE, Acting Associate Secretary 